NBSIR 74.581

Development of a Solid Sorption Tube for Sampling Hydrogen Fluoride in the Work Atmosphere

James Wing and John K. Taylor

National Bureau of Standards

Department of Commerce

Washington, D. C. 20234

October 1974

Final Report

Prepared for

National Institute for Occupational Safety and Health

Division of Laboratories and Criteria Development

Cincinnati, Ohio 45202 



\section{DEVELOPMENT OF A SOLID SORPTION TUBE FOR SAMPLING HYDROGEN FLUORIDE IN THE WORK ATMOSPHERE}

James Wing and John K. Taylor

National Bureau of Standards

Department of Commerce

Washington, D. C. 20234

October 1974

Final Report

\section{Prepared for}

National Institute for Occupational Safety and Health

Division of Laboratories and Criteria Development

Cincinnati, Ohio 45202

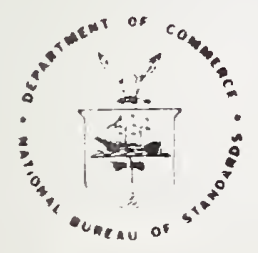

U. S. DEPARTMENT OF COMMERCE, Frederick B. Dent, Secretary NATIONAL BUREAU OF STANDARDS, Richard W. Roberts. Director 
". .

. 
1. Introduction ............... . . . . Page

1.1 Scope of the Work. . . . . . . . . . . 1

1.2 Method of Approach . . . . . . . . . . 4

1.3 Work Coverage. . . . . . . . . . . . . 4

2. Development of Methodology . . . . . . . . 4

2.1 General Consideration. . . . . . . . . . 4

2.2 Gas Dilution System. . . . . . . . . 6

2.3 Gas Sampling System. . . . . . . . . . 6

2.4 Selection of Solid Sorbents for Hydrogen Fluoride 8

2.4.1 Literature Survey on Solid Sorbents. . . 8

2.4.2 General Considerations . . . . . . . 9

2.4.3 Collection Efficiencies. . . . . . . 10

2.5 Construction of Sorption Tubes for Hydrogen. . . 12 Fluoride

2.5.1 Specifications of Sorption Tubes . . . . 13

2.5.2 Impurities in Sodium Acetate...... 16

2.6 Analytical Methods for Hydrogen Fluoride . . . 16

2.6.1 Brief Review of Analytical Methods . . . 16

2.6.2 General Considerations . . . . . . . 17

2.6.3 Operation of Fluoride Selective Electrode. 18 Instrument

2.6.4 Procedure for Measurement of Amount of . . 20 Fluoride Collected in Sorption Tubes

2.6.5 Calibration of Fluoride Selective. . . . 20 Electrode

3. Experimental Results . . . . . . . . . . 21

3.1 Collection Efficiencies of Sodium Acetate. . . . 21

3.2 Breakthrough and Capacity of the Sorption Tube . 23

3.3 Effects of Elevated Temperatures . . . . . . 25

3.4 Effects of Humidity. . . . . . . . . . 25

3.5 Precision, Bleed-out, Storage, and Shipment. 28 Studies

3.6 Glass versus Polyethylene Tubes... . . . . 30

4. Summary and Conclusions. . . . . . . . . 30

5. Bibliography . • . . . . . . . . • • 32

APPENDIX: ANALYTICAL PROCEDURE: HYDROGEN FLUORIDE IN THE ATMOSPHERE 
1. Collection Efficiencies of Various Sorbents for. $\frac{\text { Page }}{11}$ 3 ppm Hydrogen Fluoride Gas

2. Collection Efficiencies of Sodium Acetate for . . 22 Hydrogen Fluoride Gas

3. Capacity of Sorption Tubes of Different Sizes . . 24

4. Effects of Temperature on Collection of Hydrogen. . 26 Fluoride

5. Effects of Hymidity on Collection of Hydrogen . . 27 Fluoride

6. Precision, Bleed-out, Storage, and Shipment Studies 29

7. Glass versus Polyethylene Tubes . . . . . . . 31

\section{FIGURES}

1. Gas Generating and Sampling Systems for HF. . . . 7

2. Sorption Tube for HF. . . . . . . . . . . 14

3. Pressure Drop Measurement Apparatus . . . . . 15

4. Calibration Curve of Fluoride Standard Solutions. . 19 


\section{DEVELOPMENT OF A SOLID SORPTION TUBE FOR SAMPLING}

HYDROGEN FLUORIDE IN THE WORK ATMOSPHERE

\section{ABSTRACT}

The efficiencies of several solid substances in a sorption tube for collecting trace quantities of hydrogen fluoride gas in work atmosphere have been evaluated. Reagent-grade sodium acetate crystals proved to be a very efficient sorbent for hydrogen fluoride. Its solubility in water and $\mathrm{pH}$ buffer properties are highly advantageous for subsequent fluoride determination by the ion selective electrode. Experimental results are presented for collection efficiencies of hydrogen fluoride gas at several concentration levels, flow rates, and collection times; the effects of elevated temperatures and humidity; and also breakthrough, bleedout, storage and shipment studies. Specifications for construction of the sorption tubes are also given.

\section{Introduction}

This report summarizes work on the development of a sampling procedure and a device for collecting hydrogen fluoride gas in the work atmosphere, and subsequent quantitative determination of the collected gas in the laboratory. The work is part of the program under a Memorandum of Agreement between the National Bureau of Standards and National Institute for Occupational Safety and Health. The program calls for a development of procedures and devices for personal sampling applications, and analytical methods suitable for routine laboratory use. The gas sampling medium should consist of only solid substances.

1.1 Scope of the Work

As stated in the Memorandum of Agreement, the scope of the work includes:

A. Development of sampling procedures and devices for the collection of hydrogen fluoride gas in the industrial atmosphere, including:

1. Evaluation of various solid sorbent materials.

2. Selection of an appropriate sorbent based on the following criteria. A suitable sorbent sha1l:

a. Be stable upon exposure to air flows, water vapor, temperature extremes, shipping, and storage. 
b. Retain the contaminant quantitatively during sampling, shipment, and storage up until the time of laboratory analysis.

c. Not react or degrade the contaminant in such a way as to prevent identification or change the concentration.

d. Be inexpensive to fabricate and purchase.

e. Be capable of manufacture in a manner so that reproducible collection and desorption properties can be obtained from batch to batch.

f. Be suitable for use in conjunction with personal samplers.

g. Be suitable in all respects for quantitative analysis of the collected materials.

h. Retain the substance of interest in the presence of other substances commonly present in industrial atmospheres.

i. Provide for specificity of measurement of the substance of interest, either by selective collection or by compatibility with selective analytical procedures.

3. Design of a suitable collection device containing the solid sorbent. The collection device should meet the following criteria:

a. The collection device should be as small in size and as light in weight as possible so

that it can be attached to a worker's collar or lapel to collect a breathing zone sample.

b. The resistance of the collection device to air flow should not exceed $2.54 \mathrm{~cm}$ of mercury pressure drop at a flow rate of one liter per minute through the device, or $6.35 \mathrm{~cm}$ of water pressure drop at $200 \mathrm{~cm}^{3}$ per minute.

c. There should be a method to verify that no breakthrough has occurred during sampling.

d. The collection device should have a sufficient capacity for collection of 4- to 8-hour samples at a flow rate between 50 and $200 \mathrm{~cm}^{3}$ per minute, and for 15 -minute samples at a flow rate of 1 liter per minute, for concentration ranges of 
$1 / 5$ to 5 times the threshold limit value (TLV) concentrations of hydrogen fluoride.

B. Provision of suitable methods for retrieving the contaminant from the collection device and for analyzing the level of contaminant which was collected. The present state-ofthe-art of analytical methods for hydrogen fluoride shall be investigated. Candidate methods will be experimentally evaluated for such factors as accuracy, reproducibility, and criticality of steps. A procedure will be written for the recommended method suitable for routine laboratory use.

C. Thorough evaluation of the recommended sampling and analytical methods. The scope of the evaluation shall include:

1. Assessment of the collection efficiency of the collection device.

2. Assessment of the effects of temperature and humidity on the breakthrough characteristics of the collection device.

3. Measurement of the effects of shipping and storage of samples in adverse conditions of temperature and pressure on percent recovery and analytical accuracy and precision.

4. Measurement and quantitation of any bleed-out effects during extended sampling periods.

5. Determination of the overall accuracy and precision of the recommended sampling and analytical methods, compared with known air concentrations.

6. Assessment of the ruggedness of the recommended analytical methods according to the method of W. F. Youden given in the Association of Official Analytical Chemists paper, "Statistical Procedures for Collaborative Tests", where applicable.

7. Determination of the accuracy and precision of the recommended analytical method according to American Society for Testing and Materials recommended practices.

8. Determination of the useful range of the recommended sampling and analytical methods. 
For use as a personal sampler, the collection device containing solid sorbent materials should function with high efficiency and possess a large capacity for the contaminant hydrogen fluoride. The contaminant so collected should be completely retrievable for subsequent analysis. These three processes, sorption, retrieval, and analysis, as outlined on $p 5$ could be either specific or non-specific for hydrogen fluoride. For example, capture of volatile contaminants can be achieved by the mechanisms of physical adsorption/absorption or chemical reaction, each of which may or may not be specific for hydrogen fluoride. The recovery of the contaminant or its reaction product may involve specific or non-specific chemical or physical processes. Finally, analytical methods are available for specific and non-specific determination of hydrogen fluoride. The only necessary condition here is that one of the processes should be specific for hydrogen fluoride.

\subsection{Work Coverage}

The work in this report involves construction of apparatus for continuous generation of hydrogen fluoride gas at trace levels; construction of apparatus for sampling hydrogen fluoride gas at calibrated flow rates; evaluation and selection of solid sorbents for efficient collection of hydrogen fluoride; development of a sorption tube for personal sampling applications; development of a procedure for collection and subsequent quantitative analysis of hydrogen fluoride; determination of collection efficiencies of the sorption tube at several concentration levels of hydrogen fluoride, flow rates, and collection times; and study of the effects of temperature, humidity, breakthrough, bleedout, storage, and shipment.

This report also provides specifications for construction of the sorption tube and a recommended procedure for collection and determination of hydrogen fluoride gas.

\section{Development of Methodology}

This section describes the development of methods for continuous generation and sampling of hydrogen fluoride gas, and of procedures for collection and analysis of the gas. A brief review of the literature on solid sorbents and analytical methods for hydrogen fluoride is also given.

\subsection{General Consideration}

To approximate the industrial work atmosphere, a relatively concentrated mixture of hydrogen fluoride gas was 


\section{Sorption}

I
Chemical Reaction
Physical Adsorption/Absorption

specific non-specific

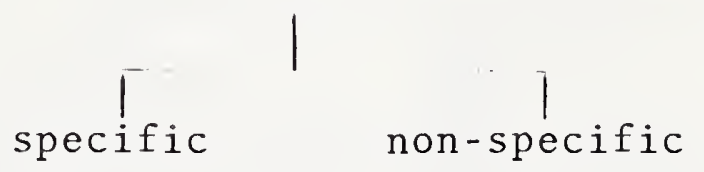

Chet

Chemical Reaction

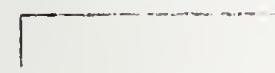

specific

$$
\text { non-specific }
$$

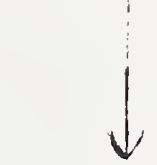

Retrieval

$$
\text { I }
$$


diluted with air rather than pure nitrogen. The hydrogen fluoride gas samples were drawn through sorption tubes by vacuum to simulate sampling by a personal sampler. Consideration was made in the selection of sorbent materials and specification of the sorption tube to conform to the work scope as outlined in Section 1.1. The recommended analytical method was one that required minimal training for efficient performance.

\subsection{Gas Dilution System}

To carry out many tests required for the selection of the solid sorbents, a reliable source of contaminant is needed. The concentration level of hydrogen fluoride required in this work ranges from 0.6 to $15 \mathrm{ppm}, i . e ., 1 / 5$ to 5 times TLV (1). Although hydrogen fluoride gas mixtures at this concentration range are available commercially, past experience indicated instability of such gas mixtures for extended periods. A cylinder of hydrogen fluoride gas mixture in nitrogen was used as a bulk source of the contaminant. The concentration of the gas at the time of use was found to be $61 \mathrm{ppm}$. This gas mixture was then dynamically diluted with in-house compressed air to the desired concentrations in a gas dilution system. Several systems of this type have been developed and used successfully for gas dilution (2). This dilution system can also be conveniently used to study the effects of humidity on the collection of the contaminant gas.

Figure 1 is a schematic drawing of the gas dilution system. It consisted essentially of a bubbler containing distilled water to saturate the in-house air, two differential flow controllers (one had a stainless steel diaphram for hydrogen fluoride), two rotameters for measurement of flow rates of air and hydrogen fluoride, and stainless steel mixing and sampling manifolds. Either thick-wall Teflon or stainless steel hardware was used wherever hydrogen fluoride gas passed. Prior to the water saturator, the in-house air was filtered through glass wool. Proper adjustment of the two rotameters $R-1$ and $R-2$ by valves $V-2$ and $V-5$, respectively, produced hydrogen fluoride gas mixtures of the desired concentrations. The use of valves V-3 and V-4 provided a choice of oil-free dry air and water-saturated air for mixing with hydrogen fluoride. The rotameters were calibrated with a wet test meter.

\subsection{Gas Sampling System}

The sampling rates required in this work range from $50 \mathrm{~cm}^{3}$ per minute to 1 liter per minute. These flow rates were obtained with the gas sampling system shown schematically in figure 1. The system consisted essentially of a three-way ball valve, two sorption tubes joined in series 


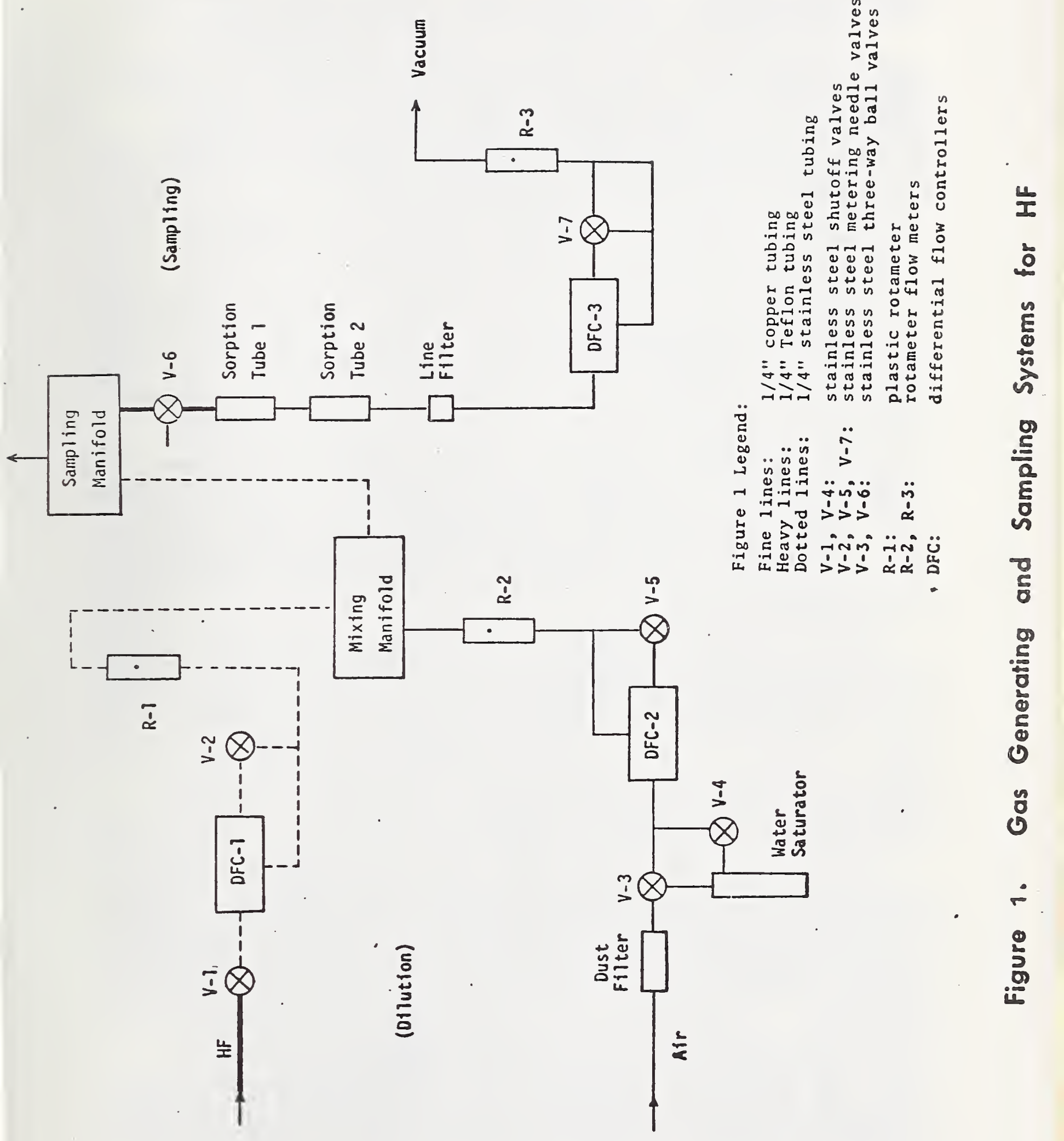


by Cajon connectors, a brass in-line filter, a differential flow controller, a rotameter, and a vacuum pump.

Gas samples were withdrawn under vacuum from the sampling manifold. When adjusting valve $V-7$ for the proper sampling rates, the three-way valve V-6 was opened to the atmosphere. The flow rates of the hydrogen fluoride-air mixture in the gas mixing manifold were always maintained at three or more times the gas sampling rates. The rotameter was calibrated with a wet test meter.

\subsection{Selection of Solid Sorbents for Hydrogen Fluoride}

\subsubsection{Literature Survey on Solid Sorbents}

Several solid substances have been reported in the 1 it erature for sorption of hydrogen fluoride in air. These include sodium bicarbonate (3), sodium carbonate (4-7), limestone (8), alumina (9), sodium formate $(10,11)$, sodium hydroxide-carbonate $(12,13)$, potassium-sodium carbonates $(14,15)$, potassium hydroxide (16), silica gel (17), and calcium oxide (18). Various collection devices have been developed, such as impregnated filter papers (3, 15, 18-20), fiber filters $(7,14,21)$, impregnated polystyrene filters (11), coated tubes or beads $(5,6,18,22)$, and packed towers (8). The Drager detector tube (23) for hydrogen fluoride uses zirconium alizarin lake on silica gel as the sorbent and color indicator.

The Intersociety Committee (18) described the use of filter papers impregnated with calcium-based fixative agents such as calcium oxide or other soluble alkalies, and cautioned that gaseous fluorides collected on glass fiber filters cannot be quantitatively removed by leaching with water. Thompson et al. at the Environmental Protection Agency (21) employed fiber filters to collect gaseous and particulate water-soluble fluorides from ambient air and recovered the fluorides by reflux with water.

Bourbon and Alary (3) found that filter papers impregnated with 1 percent sodium bicarbonate gave better recovery of fluoride than lime papers. Okita et al. (5) found that the collection efficiency for gaseous fluorides was best in a glass spiral coated with dried sodium carbonate. Hermann (6) used silver balls coated with a thin layer of sodium carbonate. A two-stage filter consisting of a membrane filter and a second membrane filter impregnated with 1 percent sodium carbonate was developed in Japan (7). Naoi (13) removed acidic gases by filters impregnated with a mixture of sodium hydroxide and carbonate. Okita (14) obtained 100 percent collection efficiency for particulate fluoride compounds by membrane filters impregnated with 
sodium and potassium carbonates. Okita et al. (15) collected gaseous hydrogen fluoride on filter papers impregnated with 1 percent sodium and potassium carbonates. At 0.05 to 1.0 ppm level, the collection efficiency was 94 percent at 40 percent relative humidity.

Gilbert et al. (8) investigated the effects of different types of 1 imestone, gas velocity and temperature, size of packing, and hydrogen fluoride concentrations on the absorption coefficient. Lobos et al. (9) used a heated alumina desiccator to absorb hydrogen fluoride, and found that the gamma-type alumina absorbed over 2 percent fluoride in a fraction of a second. Jahr (10) employed two successive filters, the first untreated and the second impregnated with sodium formate. Particulate fluorides were collected quantitatively on the first filter whereas hydrogen fluoride was found on both. However, the hydrogen fluoride on the first filter could be completely transferred to the second by heating.

Biheller and Resch (11) were able to trap more than 99 percent of hydrogen fluoride with polystyrene filters which were impregnated with 10 percent sodium formate in 50 percent alcohol. Huygen (16) compared the efficiencies of filter papers impregnated with 20 percent potassium hydroxide-10 percent glycerol, filter papers impregnated with 20 percent potassium hydroxide-10 percent triethanolamine, and bubblers containing $0.1 \mathrm{~N}$ sodium hydroxide solution. The freshly prepared filter papers had 100 percent collection efficiency at humidities greater than 25 percent, and 87 percent at zero humidity. Guilbault (20) described paper tapes impregnated with $\mathrm{Mg}-8$-hydroxylquinoline to give $\mathrm{ppb}$ detection capability by quenching of fluorescence.

\subsubsection{General Considerations}

As hydrogen fluoride is chemically a very reactive species and also a very strong acid when ionized, sorption by chemical reaction received more consideration than physical adsorption/absorption (see Section 1.2). Many inorganic fluorides are soluble in water. If the reaction product in sorption is a water-soluble fluoride, retrieval of hydrogen fluoride as a fluoride can be complete and quite convenient. Furthermore, if the final chemical analysis should be specific for fluoride, then the sorption reaction need not be specific.

For personal sampler applications, the collection device must be compact in size with high efficiency and large capacity. It follows that packed columns or tubes are more desirable than impregnated papers, tapes, membrane filters and coated tubes. 
In a preliminary screening of solid sorbents, the collection efficiencies of sodium bicarbonate powders, activated charcoal (roasted coconut shells), activated charcoal soaked with saturated sodium bicarbonate solution, firebrick soaked with saturated sodium bicarbonate solution, sodium citrate crystals, and sodium acetate crystals were evaluated. These substances in granular form were packed in glass tubings of $6 \mathrm{~mm}$ outside diameter so that the pressure drop did not exceed $2.54 \mathrm{~cm}$ of mercury at the air flow rate of 1 liter/minute.

Two tubes, connected in series, were used to evaluate collection efficiency. After sampling a given hydrogen fluoride gas mixture at a flow rate for a period, the amounts of fluoride collected in the first and second sorption tubes were determined by the method to be described in Section 2.6. The collection efficiency, E, defined as

$$
E=\frac{\left(A_{1}-B_{1}\right)}{\left(A_{1}-\overline{B_{1}}\right)+\left(A_{2}-B_{2}\right)} \times 100
$$

where $A_{1}=$ amount of fluoride collected in the first sorption tube,

$A_{2}=$ amount of fluoride collected in the second sorption tube,

$B_{1}=$ blank for the first sorption tube,

$B_{2}=b l a n k$ for the second sorption tube,

was calculated. Blanks were obtained under identical conditions but using the ambient air of the laboratory.

Table 1 is a summary of the collection efficiencies of the solid sorbent systems studied. Although sodium bicarbonate showed a relatively high collection efficiency, it had the disadvantage that it was available only in the powder. form, and the pressure drop of sorption tubes generally exceeded $2.5 \mathrm{~cm}$ mercury. Also, its efficiency of collection at the flow rate of $50 \mathrm{~cm}^{3} / \mathrm{min}$ was rather $10 \mathrm{w}$.

It was difficult to leach sodium fluoride, the reaction product of sodium salts with hydrogen fluoride, from activated charcoal and firebrick substrates. The fine particulates of the substrates in the resultant solutions had to be filtered off before analysis. No attempt was made to determine the recovery of fluoride in the leaching process. 
Table 1. Collection Efficiencies of Various Sorbents for 3 ppm Hydrogen Fluoride Gas

\section{Sorbent}

$\mathrm{NaHCO}_{3}$

Activated charcoal

Firebricks soaked with sat'd $\mathrm{NaHCO}_{3}$ sol'n

Charcoal soaked with sat'd $\mathrm{NaHCO}_{3}$ sol'n

Charcoal soaked with sat'd $\mathrm{NaHCO}_{3}$ sol'n + 5 percent glycerine

Na citrate crystals

$\mathrm{Na}$ citrate in urethane +5 percent glycerine solution

$\mathrm{Na}$ acetate crystals

${ }^{a}$ A total of 9 runs.

${ }^{b}$ A total of 6 runs.
Collection Flow Rate Collection
Time

$15 \mathrm{~min}$

$4 \mathrm{~h}$

$6 \mathrm{~h}$

$8 \mathrm{~h}$

$8 \mathrm{~h}$

$15 \mathrm{~min}$

$6 \mathrm{~h}$

$4 \mathrm{~h}$

$8 \mathrm{~h}$

$15 \mathrm{~min}$

$15 \mathrm{~min}$

$15 \mathrm{~min}$

$15 \mathrm{~min}$

$4 \mathrm{~h}$

$15 \mathrm{~min}$

$15 \mathrm{~min}$ $\frac{\mathrm{cm}^{3} / \mathrm{m}}{1050}$

211

211

50

1050

211

41

50

1050

1050

1050

$89.0,90.3$

$93.1,97.4$

90.7

82.8

52.5

70.6

$61.0,85.0$

1050

211

12.9

11.8

1050

31.5

1050 
There was evidence that water was desirable for the reaction of sodium in the solid sorbents with hydrogen fluoride, as shown by the higher collection efficiency (31.5 percent) of sodium citrate plus 5 percent glycerine in water over the dry salt. Activated charcoal soaked with saturated sodium bicarbonate solution also gave higher collection efficiencies when 5 percent glycerine was present.

Sodium acetate was selected as the sorbent for hydrogen fluoride on the following basis:

1. high collection efficiency,

2. acetate acts as a pH buffer in the fluoride selective electrode method of analysis,

3. readily available as reagent grade in the 20-40 mesh size,

4. relatively inexpensive,

5. chemical stability of both sodium acetate and the reaction product sodium fluoride under normal conditions,

6. presence of three molecules of water of hydration per formula weight, highly desirable for the reaction with hydrogen fluoride in air,

7. non-toxic, non-irritating, non-corrosive, nonobnoxious,

8. high solubilities of both sodium acetate and sodium fluoride in water,

9. high melting points of sodium acetate and sodium fluoride, $58^{\circ} \mathrm{C}$ and $992^{\circ} \mathrm{C}$, respectively.

2.5 Construction of Sorption Tubes for Hydrogen Fluoride

The sorption tubes were constructed according to the procedure given below. The reagent-grade sodium acetate used was pooled from bottles from three different suppliers. Crystals of 20 to 40 mesh were separated from the bulk in the reagent bottles by sieving. The only apparent difference among these three sources of sodium acetate was in the distribution of particle size. An average of 10 percent of the sodium acetate in the bulk was of 20 to 40 mesh. No attempt was made to determine the distribution of particle size in the 20 to 40 mesh crystals. 
Figure 2 is a drawing of the sorption tube. Although the specifications call for Pyrex glass tubing, polyethylene tubing should be preferable to avoid reaction of hydrogen fluoride with the glass surfaces. Subsequent studies showed a slight loss of hydrogen fluoride when Pyrex tubes were used.

For use as a personal sampler, two sorption tubes may be joined in series with a piece of polyethylene tubing so that the second sorption tube acts as a breakthrough indicator. However, the high capacity of the collection tube makes this virtually unnecessary.

\subsubsection{Specifications of Sorption Tubes}

1. Join two Pyrex glass tubings of $6 \mathrm{~mm}$ outside diameter and $3 \mathrm{~cm}$ long to a Pyrex glass tube of $13 \mathrm{~mm}$ outside diameter and $4 \mathrm{~cm}$ long. Make very slight constrictions at the joints.

2. Introduce a wad of loose surgical cotton, about $5 \mathrm{mg}$, inside the tube.

3. Blow dry air inside the tube to arrest the cotton at the "groin" of the tube.

4. With the aid of a small funnel and a piece of Tygon tubing, fill the tube with 20 to 40 mesh reagent-grade sodium acetate crystals, $\mathrm{NaC}_{2} \mathrm{H}_{3} \mathrm{O}_{2} \cdot 3 \mathrm{H}_{2} \mathrm{O}$, (about $3 \mathrm{~g}$ ) up to the "neck". Gently tap the tube to help the crystals settle. Do not use crystals that are lumped together.

5. Insert a wad of 1 oose surgical cotton, about $4 \mathrm{mg}$, on top of the sodium acetate crystals.

6. Mark an arrow on the outside wall of the tube to indicate the air flow direction, i.e., the same direction as the air that was used in blowing the cotton.

7. Connect the sorption tube to an orifice which has an opening to pass air at $11 / \mathrm{min}$. Connect the orifice to a manometer and vacuum with a tee. Figure 3 is a drawing of the pressure drop measurement apparatus.

8. Turn the vacuum on to check the pressure drop. Reject sorption tubes with a pressure drop over $2.54 \mathrm{~cm} \mathrm{Hg}$.

9. When not in use, tightly seal both ends of the sorption tube with plastic end caps. Do not store tubes at temperatures above $40^{\circ} \mathrm{C}$. 


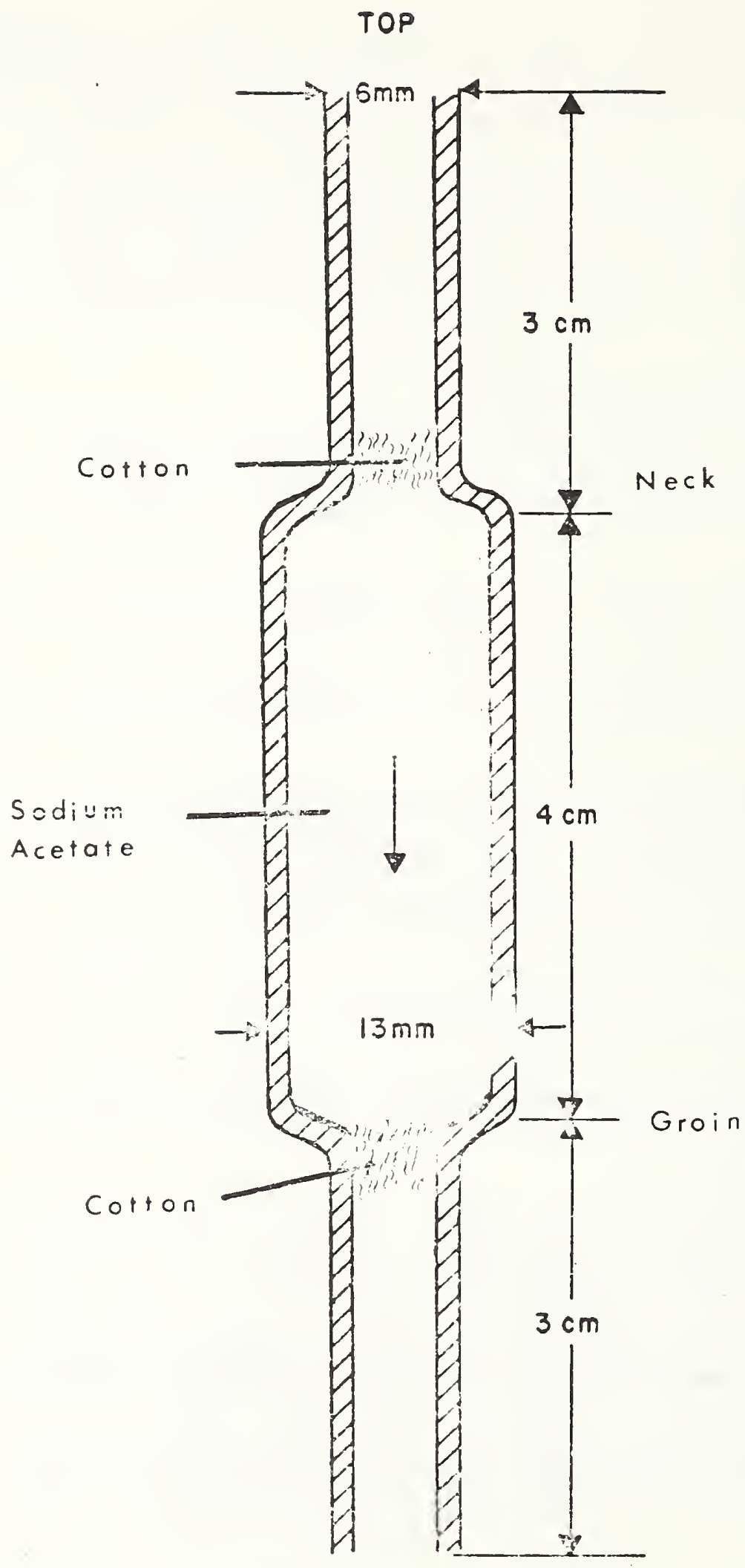

Fuve 2, Sorion Tube for HF 


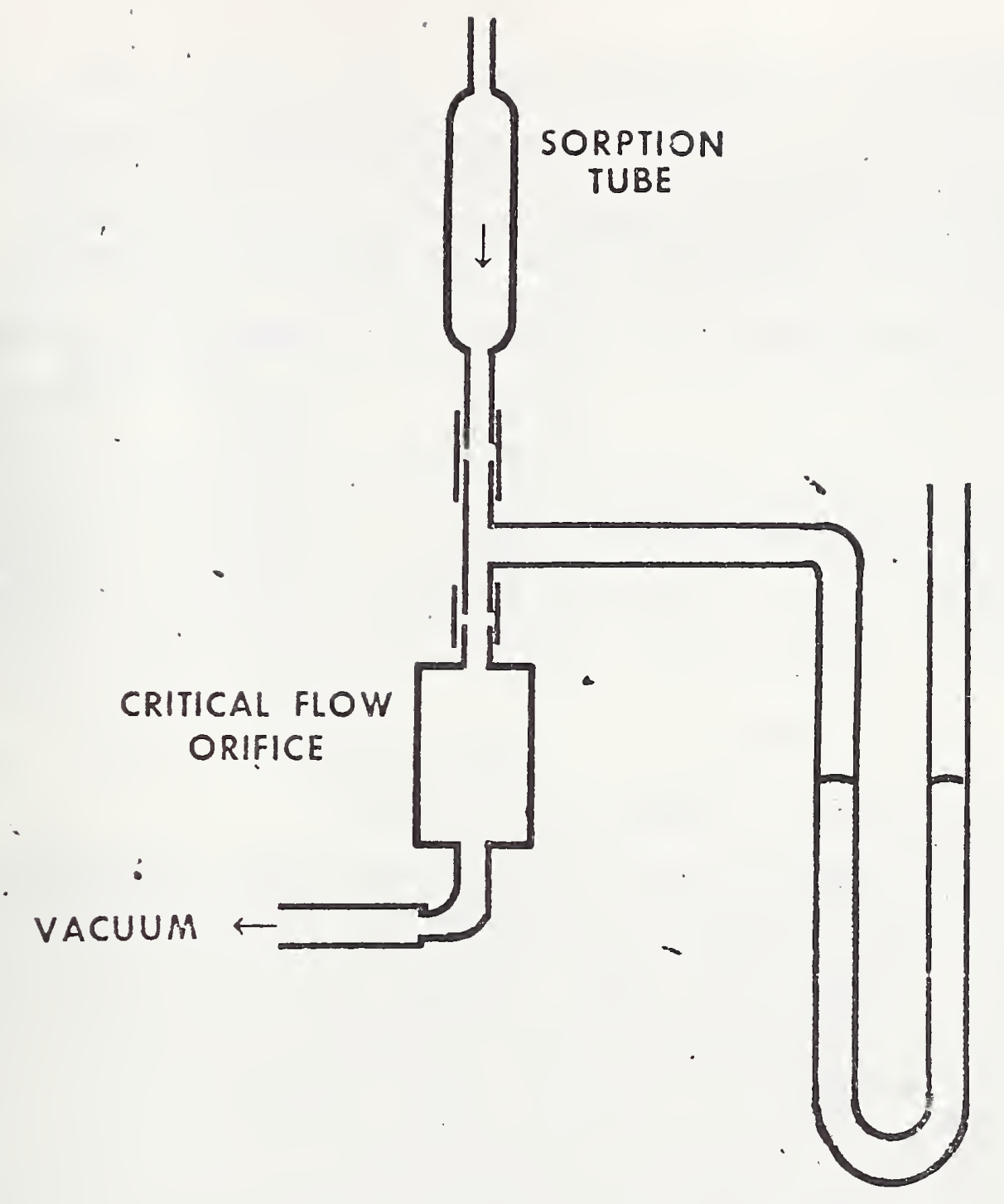

MANOMETER

MANOMETER 
The sodium acetate used in the experiments contained the following impurities, as 1isted on the labels of the reagent bottles. None of these impurities is expected to interfere with the fluoride selective electrode analysis.

Impurities (in percent)

Insoluble matter

Chloride

Phosphate

Sulfate

$\mathrm{Ca}, \mathrm{Mg}$, and $\mathrm{R}_{2} \mathrm{O}_{3}$ precipitates

Heavy metals as $\mathrm{Pb}$

Iron

Potassium

Ammonium
Supplier A Supplier B Supplier C

0.003
0.0004
0.0003
0.001
0.005
0.0002
0.0002
0.001

0.003

0.0004

0.005

0.001

0.0005

0.002

0.010

0.0005

0.0005

0.005

0.001
0.001

0.0003

0.0002

0.0004

0.003

0.0002

0.0001

0.005

\subsection{Analytical Methods for Hydrogen Fluoride}

2.6.1 Brief Review of Analytical Methods

Many analytical methods for hydrogen fluoride are now available. As the number of references on fluoride determination is quite large, only a few representatives are cited here. In general, these methods may be classified as ion selective electrode $(21,24)$, colorimetry $(18,23,24)$, titrimetry (18), spectrophotometry $(18,25)$, photometry $(6,22,24)$, fluorimetry $(20,25,26)$, gas ionization (27), bioassay (28), spot test $(29,30)$, and nuclear activation analysis $(31,32)$. The first four methods are more applicable to the present work than the others. Below is a brief description of their basic principles, interferences, and range or limits of detection.

The fluoride selective electrode gives Nerstian response to fluoride ion concentrations from above $1 \mathrm{M}$ to $10^{-5} \mathrm{M}$, and only hydroxide ion seems to interfere with this response. With the $\mathrm{pH}$ of the sample solution maintained between 5 to 7 by a pH buffer and the presence of a polyvalent anion to break up any complexing agent, selectivity is excellent. The 1 imit of detection is $100 \mathrm{~kg} / 1$.

The colorimetric method measures the change of color intensity of a dye lake by the reaction of fluoride ions, using either a color comparator or a photometer. In the SPADNS method, sodium 2-(parasulfophenylazo)-1,8-dihydroxy-3, 6-naphthalene disulfonate, also called 4,5-dihydroxy-3(parasulfophenylazo)-2,7-naphthalene disulfonic acid trisodium salt, combine with zirconyl chloride to form the dye lake. Sodium alizarinsulfonate, also known as alizarin 
red S, may also be used. The range of applicability is 0.05$1.4 \mathrm{mg} / 1$. Interferences include alkalinity, aluminum, ch1oride, iron, hexametaphosphate, phosphate, and sulfate.

In titrimetry, the sample solution containing fluoride and sodium alizarinsulfonate is titrated against thorium nitrate. Interferences are aluminum, barium, calcium, iron, thorium, titanic, vanadyl, zirconium, phosphate and sulfate ions. The range and sensitivity are 5-50 $\mathrm{\mu g}$ in the total sample for titration.

In spectrophotometry, the change in absorbance of the solution containing a metal dye complex, such as zirconiumeriochrome cyanine $R$ or zirconium-SPADNS, by fluoride is measured. The range of applicability is 0.02-1.4 $\mathrm{mg} / 1$. Lanthanum alizarin complexone, commonly called alizarin fluorine blue, may also be used, and the range is lowered: 0.015-0.5 mg/1. Interferences include aluminum, iron, phosphate, and sulfate.

\subsubsection{General Considerations}

The ion selective electrode method for fluoride determination was chosen on the basis of its excellent selectivity for fluoride and simplicity in operation. The necessary equipment in this method includes a fluoride selective electrode, a calomel reference electrode, a $\mathrm{pH}$ meter with millivolt mode, and a magnetic stirrer. The concentration of fluoride in a sample solution is obtained from the millivolt reading and a calibration curve. The latter is established from a plot of millivolt response versus fluoride concentrations of sodium fluoride standard solutions. The standard solutions are prepared from known weights of dried sodium fluoride dissolved in $0.88 \mathrm{M}$ sodium acetate solution containing $0.3 \mathrm{~g}$ sodium citrate per liter. The procedure for operation of the fluoride selective electrode instrument is given in the next section.

At the conclusion of gas sampling, the amount of fluoride collected in the sorption tube may be determined according to the procedure given in Section 2.6.4. In the preliminary screening of solid sorbents, the sorbents sodium bicarbonate and citrate were dissolved in sodium nitrate solution to give the same ionic strength as the standard solutions. For charcoal and firebricks, the sodium fluoride was leached out from the substrates with $25 \mathrm{ml}$ water, and the proper amounts of sodium acetate and citrate were added to the solutions.

The amount of fluoride collected, in moles of fluorine, was calculated from the following equation: 


$$
A=\frac{25 C}{1000}
$$

where $A=$ amount of fluoride collected in the sorption tube, and

$$
\mathrm{C}=\text { molar concentration of fluoride. }
$$

The concentration of hydrogen fluoride, in parts per million (ppm), in the gas samples was calculated from the following equation:

$$
\text { ppm } H F=\frac{A \times 24.5 \times 10^{6}}{\mathrm{~T} \times \mathrm{R}}
$$

where $\mathrm{T}=$ total collection time in minutes, and

$R=$ flow rate of gas sample in liters per minute at standard temperature-pressure condition.

To study the effects of sodium acetate concentration on millivolt response, a series of sodium fluoride standards in $0.55 \mathrm{M}$ sodium acetate solutions was prepared. Figure 4 shows the calibration curves of the standard solutions in both $0.88 \mathrm{M}$ and $0.55 \mathrm{M}$ sodium acetate solutions. The effect of sodium acetate concentration was negligible.

2.6.3 Operation of Fluoride Selective Electrode Instrument

The following directions apply to the use of the ion selective electrode:

1. Connect the fluoride and the reference electrodes to the $\mathrm{pH}$ meter. Set the meter to "standby" position.

2. Transfer the sample solution to a 50-m1 polyethylene beaker. Add 2 drops of $0.5 \mathrm{~N}^{-} \mathrm{HNO}_{3}$ to adjust the $\mathrm{pH}$ of the solution to 6.8 .

3. Place the electrodes in the sample solution.

4. Place a Teflon coated magnetic stirrer in the beaker and turn on the variable transformer to provide gentle stirring of the solution.

5. At the end of 15 minutes, set the meter to millivolt mode and record the millivolt reading.

6. Set the meter back to "standby" position. 


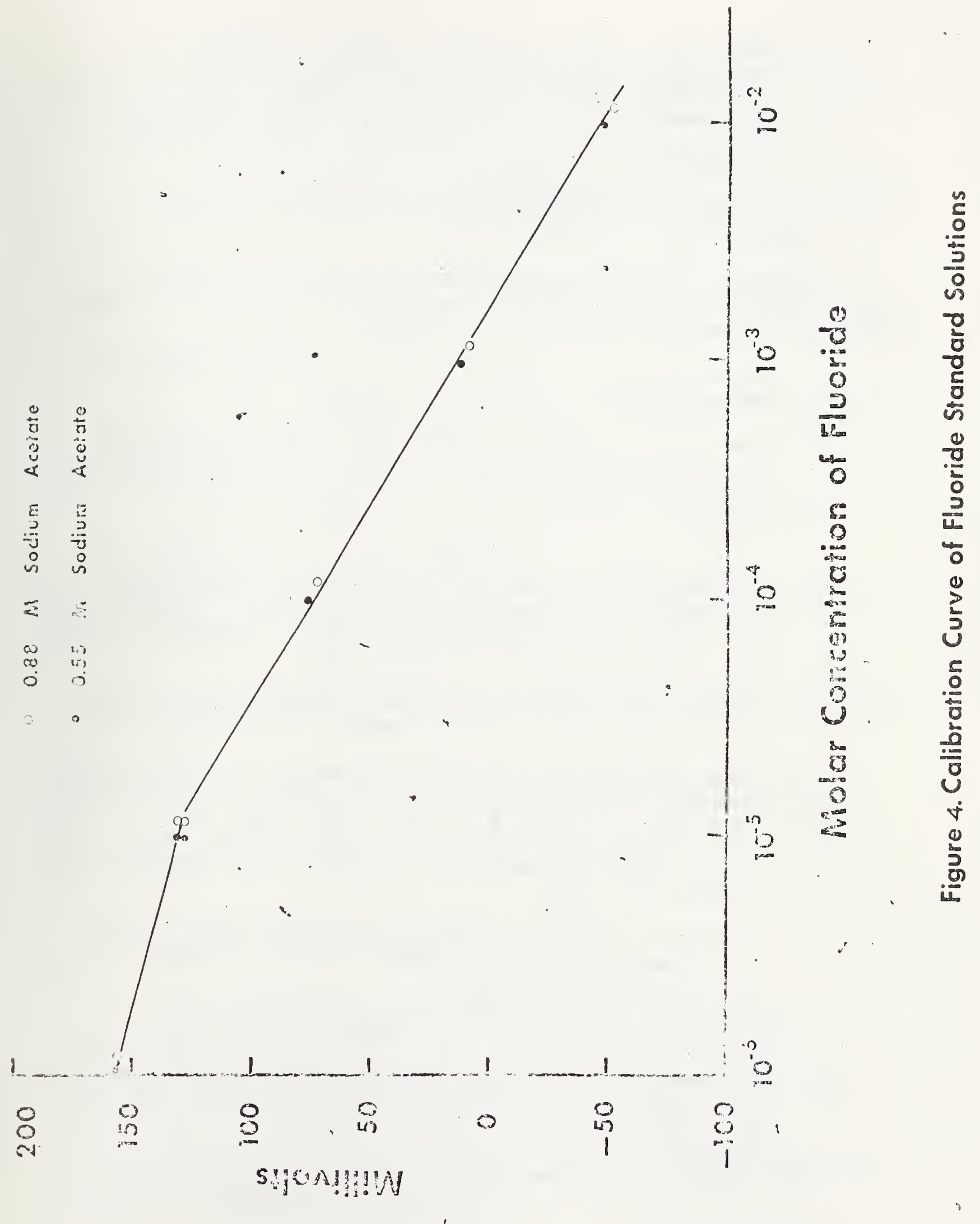


7. Empty the contents of the beaker. Rinse the electrodes thoroughly with distilled water. Wipe the electrodes dry with soft tissue. The electrodes are now ready for measurement of another sample. When not in use, the electrodes should be immersed in distilled water.

2.6.4 Procedure for Measurement of Amount of Fluoride Collected in Sorption Tubes

Prepare a stock solution containing $0.3 \mathrm{~g}$ sodium citrate per liter in distilled water, and use it for dissolution of the sodium acetate.

1. Disconnect the sorption tube from the sampling apparatus.

2. Use a stiff wire or a pair of straight corrugated forceps to remove the top wad of cotton in the sorption tube and place the cotton in a polyethylene beaker.

3. Insert the top end of the sorption tube into the neck of a 25-m1 volumetric flask, and empty the sodium acetate crystals into the flask. Gently tap the tube against the flask to get as many as possible of the crystals into the flask.

4. With a stiff wire, break loose the bottom wad of cotton. Keep the cotton inside the sorption tube.

5. Rinse the inside walls of the sorption tube and the cotton with 15-18 m1 stock citrate solution. Make sure all the rinse goes into the flask.

6. Remove the sorption tube from the neck of the volumetric flask.

7. Rinse the cotton in the polyethylene beaker with $5 \mathrm{ml}$ stock citrate solution. Add the rinse to the 25-m1 volumetric flask.

8. Dissolve the sodium salts completely.

9. Add enough stock citrate solution to make $25 \mathrm{~m} 1$. Mix thoroughly. The solution is now ready for fluoride concentration determination.

2.6.5 Calibration of Fluoride Selective Electrode

Prepare a series of sodium fluoride standard solutions as follows: 
1. Prepare a stock solution containing $120 \mathrm{~g}$ sodium acetate and $0.3 \mathrm{~g}$ sodium citrate per liter in distilled water. Use this stock solution for dissolution and dilution of the sodium fluoride below.

2. Dissolve $420 \mathrm{mg}$, weighted to the accuracy of \pm 0.1 $\mathrm{mg}$, of dried sodium fluoride and dilute it to 100.0 $\mathrm{m} 1$ in a volumetric flask. This makes the $10^{-1} \mathrm{M}$ solution.

3. Dissolve $420 \mathrm{mg}$, weighted to the accuracy of \pm 0.1 $\mathrm{mg}$, of dried sodium fluoride, and dilute it to 1.000 liter in a volumetric flask. This makes the $10^{-2} \mathrm{M}$ solution.

4. Pipette $10.0 \mathrm{~m} 1$ of the $10^{-1} \mathrm{M}$ solution and dilute it to 1.000 liter in a volumetric flask. This makes the $10^{-3} \mathrm{M}$ solution.

5. Pipette $10.0 \mathrm{ml}$ of the $10^{-2} \mathrm{M}$ solution and dilute it to 1.000 liter in a volumetric flask. This makes the $10^{-\frac{1}{4}} \mathrm{M}$ solution.

6. Pipette $1.00 \mathrm{ml}$ of the $10^{-2} \mathrm{M}$ solution and dilute it to 1.000 liter in a volumetric flask. This makes the $10^{-5} \mathrm{M}$ solution.

7. Pipette $1.00 \mathrm{ml}$ of the $10^{-3} \mathrm{M}$ solution and dilute it to 1.000 liter in a volumetric flask. This makes the $10^{-6} \mathrm{M}$ solution.

Store al1 the sodium fluoride standard solutions in polyethylene bottles. Use $25 \mathrm{~m} 1$ of each of these solutions for calibration periodically. Follow the procedure given in Section 2.6.3. Plot the millivolt response against the calculated concentrations of sodium fluoride.

\section{Experimental Results}

3.1 Collection Efficiencies of Sodium Acetate

Table 2 summarizes the collection efficiencies of sodium acetate crystals for hydrogen fluoride at room temperatures $\left(23.9^{\circ}\right.$ to $\left.25.5^{\circ} \mathrm{C}\right)$. These experimental runs were made in random order and not in the sequence as shown in table 2. It appears that $3 \mathrm{~g}$ of sodium acetate in 20 to 40 mesh was sufficient to remove completely hydrogen fluoride from air having concentration of hydrogen fluoride ranging from 0.5 to $16 \mathrm{ppm}$ for the collection times and flow rates specified in Section 1.1 . 
Table 2. Collection Efficiencies of Sodium Acetate for Hydrogen Fluoride Gas

Collection Flow rate

Time

$15 \min$

$15 \mathrm{~min}$

$15 \mathrm{~min}$

$15 \mathrm{~min}$

$15 \mathrm{~min}$

$15 \mathrm{~min}$

$15 \mathrm{~min}$

$15 \mathrm{~min}$

$15 \mathrm{~min}$

$15 \mathrm{~min}$

15 min

$15 \mathrm{~min}$

$4 \mathrm{~h}$

$4 \mathrm{~h}$

$4 \mathrm{~h}$

$4 \mathrm{~h}$

$4 \mathrm{~h}$

$4 \mathrm{~h}$

$4 \mathrm{~h}$

$4 \mathrm{~h}$

$4 \mathrm{~h}$

$4 \mathrm{~h}$

$8 \mathrm{~h}$

$8 \mathrm{~h}$

$8 \mathrm{~h}$

$8 \mathrm{~h}$

$8 \mathrm{~h}$

$8 \mathrm{~h}$

$8 \mathrm{~h}$

$8 \mathrm{~h}$

\section{$\mathrm{cm}^{3} / \mathrm{min}$}

916

916

916

916

916

1010

1010

1010

1010

1010

1010

1010

52

52

52

52

52

188

188

198

198

198

\section{2}

52

52

52

188

198

198

198

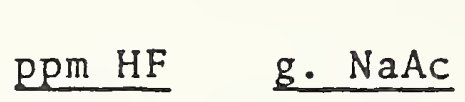

4.90

3.70

4.64

5.57

0.48

0.51

0.57

0.63

0.70

3.54

15.8

0.69

0.74

0.81

5.00

15.2

4.93

5.11

0.57

3.09

15.4

0.74

2.21

4.64

16.4

5.43

0.57

4.37

15.8
1.87

1.87

3.0

3.0

3.0

3.0

3.0

3.0

3.0

3.0

3.0

3.0

3.0

3.0

3.0

3.0

3.0

1. 87

3.0

3.0

3.0

3.0

3.0

3.0

3.0

3.0

3.0

3.0

3.0

3.0
Collection

Efficiency

94.8

100

100

99.7

100

100

100

100

100

100

100

100

100

100

100

100

99.3

100

100

100

100

100

100

100

100

100

100

100

100 
A gas mixture of $15 \mathrm{ppm}$ hydrogen fluoride was passed continuously through two sorption tubes at a flow rate of $1.01 \mathrm{l} / \mathrm{min}$. At $15 \mathrm{minute}$ intervals, the second tube was replaced with another sorption tube and its fluoride content analyzed. A total of 32 second sorption tubes was thus obtained and analyzed. The first sorption tube had collected $5.89 \mathrm{mg}$ hydrogen fluoride. No fluoride was found in any of the 32 second sorption tubes in the 8 hours of collection.

In another similar experiment, the hydrogen fluoride from the cylinder was fed without dilution through two sorption tubes in series, at the flow rate of $1.01 \mathrm{l} / \mathrm{min}$. Every 4 hours, the second tube was replaced and analyzed. Again, no breakthrough was detected in the second tubes after collection of a total of $46 \mathrm{mg}$ hydrogen fluoride in the first sorption tube. However, the inside walls of the first sorption tube above the sodium acetate crystals were etched at the end of the 16 hour run, indicating reaction of hydrogen fluoride with the glass surfaces.

The capacity of two smaller sorption tubes was a1so studied. Hydrogen fluoride gas, without dilution, was passed through two sorption tubes in series, each of which was $4 \mathrm{~cm}$ long with $10 \mathrm{~mm}$ outside diameter and contained $1.4 \mathrm{~g}$ sodium acetate. The sample flow rate was $1.01 \mathrm{l} / \mathrm{min}$. At the end of 15 minutes, the fluoride contents of these two tubes were determined. The experiment was repeated with two sorption tubes of the same length but of $8 \mathrm{~mm}$ outside diameter, each of which contained $0.8 \mathrm{~g}$ sodium acetate. The sample flow rate was $198 \mathrm{~cm}^{3} / \mathrm{min}$ and collection time was 5 hours. The results are tabulated in table 3 .

These smaller sorption tubes also possessed 100 percent collection efficiency, and no breakthrough was observed after collecting more than $5 \mathrm{mg}$ of hydrogen fluoride in the $10 \mathrm{~mm}$ tube and more than $17 \mathrm{mg}$ in the $8 \mathrm{~mm}$ tube. However, these tubes exhibited a pressure drop far higher than the $2.54 \mathrm{~cm}$ mercury specified in Section 1.1 .

The amount of fluoride collected, column 6 of table 3, was computed from the fluoride analysis results, and not from the sample flow rate, collection time, and concentration of the hydrogen fluoride gas. When the last two experiments were performed, the pressure inside the hydrogen fluoride cylinder was below $203 \times 10^{3}$ pascal ( 15 pounds per square inch above atmosphere), and the concentration of hydrogen fluoride was much higher than the original value of $61 \mathrm{ppm}$. 


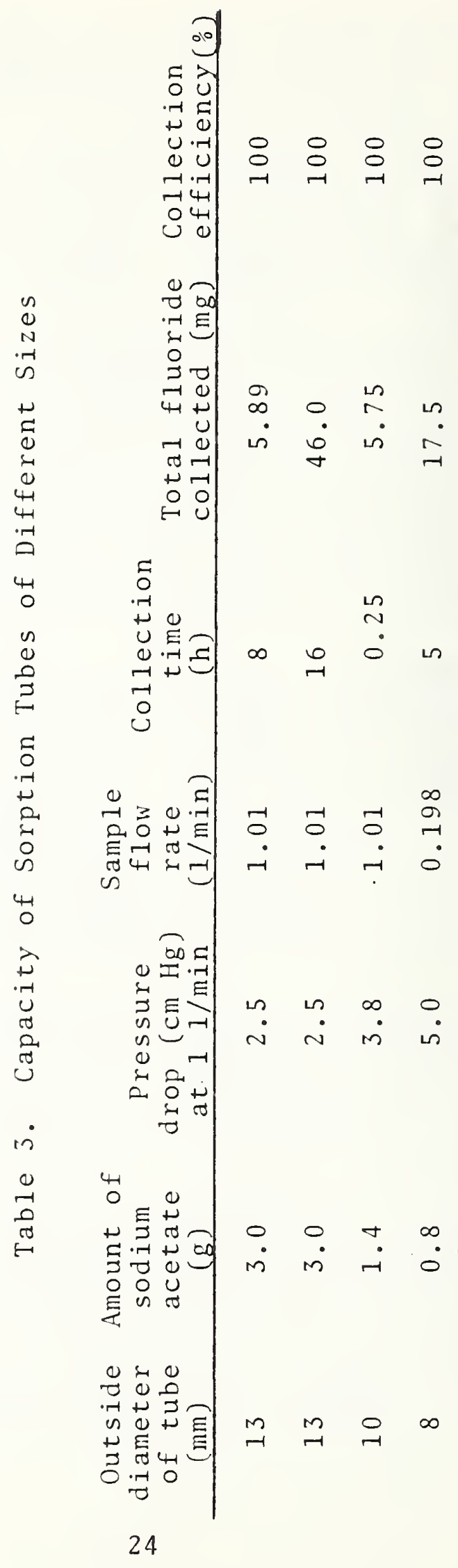


A Pyrex glass tube of $13 \mathrm{~mm}$ outside diameter and $25 \mathrm{~cm}$ long was placed in front of two sorption tubes, all in series and all wrapped with a heating tape. Heat was generated at a constant rate, and the temperature inside the $25 \mathrm{~cm}$ tube was measured by a thermometer with air flowing at $52 \mathrm{~cm}^{3} / \mathrm{min}$. A hydrogen fluoride gas sample was withdrawn through this assembly at a flow rate of $52 \mathrm{~cm}^{3} / \mathrm{min}$. The experiment was repeated with the heating tape removed and with two new sorption tubes.

Table 4 is a summary of the experimental results for two different collection times. Together with the experimental data presented in table 2, it is concluded that the collection efficiency of sodium acetate for hydrogen fluoride was 100 percent at temperatures ranging from $23.9^{\circ} \mathrm{C}$ to $38.0^{\circ} \mathrm{C}$. However, there was a loss of 9 percent of hydrogen fluoride at the elevated temperatures, as shown in the last column in table 4. Possibly, part of the hydrogen fluoride reacted with the inside walls of the Pyrex tubes with a higher kinetic rate at the elevated temperatures than at the room temperatures.

\subsection{Effects of Humidity}

With the water saturator turned on (see Figure 1), it was possible to generate air-hydrogen fluoride mixtures with various relative humidities by adjusting valves $V-2$ and $V-5$. The samples were withdrawn through two sorption tubes in series at a flow rate of $1.011 / \mathrm{min}$ for 15 minutes. The experiment was repeated with the water saturator turned off and with two new sorption tubes. The amount of fluoride in the sorption tubes was determined after the collection.

The collection efficiencies in both the wet and dry cases were 100 percent. However, the collection efficiency as defined in Section 2.4 .3 is a relative quantity. When comparing the absolute amounts $\left(A_{1}-B_{1}\right)$, of fluoride collected, it was found that the fluoride collected from the wet air was only 76.7 percent of that from the dry mixture.

In the next experiment, the stainless steel mixing and sampling manifolds and tubings were replaced by polyethylene manifolds and tubings. Again, the collection efficiencies were 100 percent in al1 cases. But the amount of fluoride collected from the wet air was now 96 percent of that from the dry mixture. Finally, sorption tubes were constructed from polyethylene tubing, and the experiments were repeated at three relative humidities. The results are summarized in table 5 . 
Table 4. Effects of Temperature on Collection of Hydrogen Fluoride

\begin{tabular}{|c|c|c|c|c|c|}
\hline $\begin{array}{c}\text { Temperature } \\
\left({ }^{\circ} \mathrm{C}\right)\end{array}$ & $\begin{array}{c}\text { Collection } \\
\text { time } \\
(\mathrm{h})\end{array}$ & $\begin{array}{l}\text { Collection } \\
\text { efficiency }\end{array}$ & $\begin{array}{r}\mathrm{ppm} \\
\mathrm{HF} \\
\end{array}$ & $\begin{array}{r}\text { Net moles } \\
\text { F collected } \\
\times 10^{-6} \\
\end{array}$ & $\begin{array}{l}\text { Ratio of moles } \\
\text { F collected } \\
\text { (elevated temp/ } \\
\text { room temp) }\end{array}$ \\
\hline $\begin{array}{l}36.0 \\
25.0\end{array}$ & $\begin{array}{l}1 \\
1\end{array}$ & $\begin{array}{l}100 \\
100\end{array}$ & $\begin{array}{l}5.2 \\
5.2\end{array}$ & $\begin{array}{l}0.60 \\
0.66\end{array}$ & 0.91 \\
\hline $\begin{array}{l}38.0 \\
25.4\end{array}$ & $\begin{array}{l}3 \\
3\end{array}$ & $\begin{array}{l}100 \\
100\end{array}$ & $\begin{array}{l}22.9 \\
22.9\end{array}$ & $\begin{array}{l}7.98 \\
8.73\end{array}$ & 0.914 \\
\hline
\end{tabular}


Table 5. Effects of Humidity on Collection of Hydrogen Fluoride

\begin{tabular}{ccccc}
$\begin{array}{c}\text { Humidity } \\
\text { (\%water } \\
\text { saturation) }\end{array}$ & $\begin{array}{c}\text { Mixing and } \\
\text { Sampling } \\
\text { Manifolds }\end{array}$ & $\begin{array}{c}\text { Sorption } \\
\text { Tubes }\end{array}$ & $\begin{array}{c}\text { Collection } \\
\text { efficiency }\end{array}$ & $\begin{array}{c}\text { Ratio of } \\
\text { collected } \\
\text { (wet/dry) }\end{array}$ \\
\hline $\begin{array}{l}59.8 \\
\text { stainless stee } 1\end{array}$ & Pyrex & 100 & 0.767 \\
59.8 & polyethylene & Pyrex & 100 & 0.963 \\
59.8 & polyethylene & polyethylene & 100 & 1.00 \\
79.3 & polyethylene & polyethylene & 100 & 1.00 \\
18.4 & polyethylene & polyethylene & 100 & 1.00
\end{tabular}


Apparently, part of hydrogen fluoride reacted with water vapor, and the product(s) then reacted with the stainless steel walls of the gas dilution and sampling systems. There was indication that hydrogen fluoride also reacted with the glass surfaces of the sorption tubes to the extent of 3.7 percent.

3.5 Precision, Bleed-out, Storage, and Shipment Studies

A total of 20 collections of hydrogen fluoride gas was made under identical experimental conditions, i.e., 15 minutes of collection time at a flow rate of $1.01 \mathrm{l} / \mathrm{min}$ and hydrogen fluoride concentration of $3 \mathrm{ppm}$. The 20 sorption tubes so obtained were distributed, in random order, for the following studies.

Four were analyzed for the fluoride content immediately. Four were stored for 35 days at room temperature and then analyzed for fluoride content. Four were stored for 70 days at room temperature and then analyzed.

Four days after the collection, four sorption tubes were sent to the National Institute for Occupational Safety and Health. Two were returned immediately and the other two were returned one week later.

Two sorption tubes were kept in a water-saturated atmosphere at room temperature for 70 days, and then analyzed.

One sorption tube was flushed with ambient air for 6 hours with a second tube in series. Another was flushed in the same manner for 24 hours. The fluoride contents in the first and the second tubes were analyzed.

The results are summarized in table 6, together with the history of the sorption tubes. The samples were collected in the alphabetical order of the sample labels, but they were analyzed in random order. The solution resulting from each sample was measured 7 times, and the average and estimated standard deviation are listed in the second and third columns respectively. For each group of samples receiving the same or similar treatment, the average and standard deviation are also computed and 1 isted in table 6.

A statistical analysis of the data shows no significant correlation among these 20 samples. A slight but inconclusive trend is observed with storage. One sample (T) has a low value, but the overall average of 75.2 includes this value. 
Table 6. Precision, Bleed-out, Storage, and Shipment Studies

\begin{tabular}{|c|c|c|c|}
\hline $\begin{array}{l}\text { Sample } \\
1 \mathrm{abel} \\
\end{array}$ & $\begin{array}{l}\text { Average } \\
\text { mv reading }\end{array}$ & $\begin{array}{l}\text { Standard } \\
\text { deviation (mv) }\end{array}$ & History \\
\hline $\begin{array}{l}\text { A } \\
\text { C } \\
\mathrm{H} \\
\mathrm{T}\end{array}$ & $\begin{array}{l}75.4 \\
75.3 \\
74.8 \\
73.2 \\
74.7 \pm 1.0\end{array}$ & $\begin{array}{l}0.4 \\
0.4 \\
0.3 \\
0.6\end{array}$ & Analyzed immediately \\
\hline $\begin{array}{l}\text { D } \\
\text { L } \\
\text { O } \\
\text { R }\end{array}$ & $\begin{array}{l}76.9 \\
75.0 \\
75.6 \\
74.7 \\
75.6 \pm 1.0\end{array}$ & $\begin{array}{l}0.3 \\
0.7 \\
0.8 \\
0.7\end{array}$ & $\begin{array}{l}\text { Stored for } 35 \text { days at room } \\
\text { temperature }\end{array}$ \\
\hline $\begin{array}{l}B \\
E \\
J \\
M\end{array}$ & $\begin{array}{l}76.4 \\
75.9 \\
76.4 \\
75.3 \\
76.0 \pm 0.5\end{array}$ & $\begin{array}{l}0.5 \\
0.7 \\
0.7 \\
0.7\end{array}$ & $\begin{array}{l}\text { Stored for } 70 \text { days at room } \\
\text { temperature }\end{array}$ \\
\hline $\begin{array}{l}K \\
P \\
G \\
Q\end{array}$ & $\begin{array}{l}75.1 \\
74.3 \\
75.5 \\
74.4 \\
74.8 \pm 0.6\end{array}$ & $\begin{array}{l}0.7 \\
1.0 \\
1.0 \\
0.7\end{array}$ & $\begin{array}{l}\text { Sent to NIOSH, returned } \\
\text { immediately } \\
\text { Sent to NIOSH, returned one week } \\
\text { later }\end{array}$ \\
\hline I & $\begin{array}{l}75.6 \\
74.2 \\
74.9 \pm 1.0\end{array}$ & $\begin{array}{l}0.5 \\
0.9\end{array}$ & $\begin{array}{l}\text { Flushed with air for } 24 \text { hours } \\
\text { Flushed with air for } 6 \text { hours }\end{array}$ \\
\hline $\begin{array}{l}F \\
S\end{array}$ & $\begin{array}{l}74.5 \\
74.8 \\
74.6 \pm 1.0\end{array}$ & $\begin{array}{l}0.6 \\
0.9\end{array}$ & $\begin{array}{l}\text { Stored in water-saturated } \\
\text { atmosphere }\end{array}$ \\
\hline
\end{tabular}

Average of $75.2 \pm 0.87$

20 samples 
The overall standard deviation of $\pm 0.87 \mathrm{mv}$ corresponds to a relative standard deviation of \pm 3.4 percent in fluoride concentration. This is a measure of the sample variability.

No bleed-out was obtained in the sorption tubes that were flushed with ambient air.

\subsection{Glass versus Polyethylene Tubes}

As mentioned in Sections $3.2,3.3$, and 3.4 , there was evidence that hydrogen fluoride reacted with the glass surfaces of the sorption tubes. To determine the extent of the reaction more precisely, hydrogen fluoride gas, without dilution, was passed directly from the gas cylinder through Teflon tubings into two sorption tubes in series. The flow rate was $198 \mathrm{~cm}^{3} / \mathrm{min}$ and the collection time was 15 minutes. The experiment was repeated alternatively using Pyrex glass and polyethylene tubes. After collection, the fluoride content in the sorption tubes was determined. The results are presented in table 7 .

The difference of $0.7 \mathrm{mv}(44.8-44.1)$, corresponds to a loss of 3 percent of hydrogen fluoride in the glass tubes, assuming no loss of hydrogen fluoride in the polyethylene tubes. However, this may not be significant in view of the relatively large standard deviations in the measurements.

\section{Summary and Conclusions}

A collection device consisting of $3 \mathrm{~g}$ sodium acetate crystals of 20 to 40 mesh packed in a $13-\mathrm{mm}$ oD tube has a very high efficiency and capacity for removing gaseous hydrogen fluoride from air. This device collects hydrogen fluoride at the $1 / 5$ to 5 times the TLV with 100 percent efficiency, at air flow rates ranging from $50 \mathrm{~cm}^{3} / \mathrm{min}$ to $11 / \mathrm{min}$. The capacity of the device is at least $46 \mathrm{mg}$ of hydrogen fluoride. The recovery of the fluoride from the tube is expected to be quantitative, although no determination was made on the recovery.

This collection device is not specific for hydrogen fluoride. It will probably trap particulate fluorides and fluorine gas with high efficiency, and the recovery may also be complete for water-soluble fluorides. The analytical method, however, is specific for fluoride. Therefore, any water-soluble compound that ionizes to fluoride and is trapped by this device will give a high analytical result for hydrogen fluoride, to the extent of the collection efficiency of such compound. On the other hand, no interference is expected from any substance that will not form ionizable fluoride. 
Table 7. Glass versus Polyethylene Tubes Tube mv reading

Glass $\begin{array}{r}44.0 \\ 45.5 \\ 45.3\end{array}$

Polyethylene

43.6

44.3

44.3

Glass

45.0

44.8

44.3

Average

$44.8 \pm 0.6$

$44.1 \pm 0.4$ 
Although no accuracy has been established for this collection device, it is expected that the high collection efficiency of sodium acetate for hydrogen fluoride, solubility of sodium fluoride in water, and the specificity of the fluoride electrode all contribute to a high degree of reliability. The sources of error include fluctuation in air flow rates, inaccuracy in recording collection time, error in volumetric dilution, instability of the instrument response, and inaccuracy in weighing the sodium fluoride standards.

At elevated temperatures such as $36^{\circ}$ to $38^{\circ} \mathrm{C}$, there is a loss of 9 percent hydrogen fluoride, possibly resulting from reaction of hydrogen fluoride with the glass surfaces of the sorption tube. Even at room temperature, a loss of hydrogen fluoride to the extent of 3.7 percent may be realized at a 60 percent relative humidity. Such problems are eliminated if the tubes were constructed of polyethylene.

The device is stable under normal conditions. No significant deterioration was observed after storage for 70 days, shipment via air freight, and purging with air for 24 hours. The precision of the sampling and analysis is \pm 3.4 percent relative standard deviation at 3 ppm hydrogen fluoride concentration.

The 3 grams of sodium acetate crystals must be packed in a $13-\mathrm{mm}$ outside diameter tube, so that the pressure drop across the tube will be below $2.54 \mathrm{~cm}$ mercury at an air flow rate of $11 / \mathrm{min}$. A smaller diameter tube of the same length $(4 \mathrm{~cm})$ exhibits a higher pressure drop for the same flow rate. A shorter tube of the same $13 \mathrm{~mm}$ outside diam-. eter containing less than $3 \mathrm{~g}$ sodium acetate has less than 100 percent collection efficiency.

\section{Bibliography}

1. American Conference of Government Industrial Hygienists, "Threshold Limit Values for Chemical Substances and Physical Agents in the Workroom Environment with Intended Changes for 1972".

2. B. C. Cadoff, P. A. Pella, E. E. Hughes, E. P. Scheide, A. A. Angotti, and J. K. Taylor, "Development of Analytical Reference Materials and Contaminant Generation Systems", National Bureau of Standards Internal Report, NBSIR 73-411 (1973).

3. P. Bourbon and J. Alary, Determination of Fluoride Pollution by a Rapid Technique Utilizing Paper Impregnated with Soda, Bul1. INSERM 24 (1), 23-30 (1969). 
4. T. Okita, S. Yamashita, R. Sugai, H. Nakagawa, K. Kaneda, and M. Mori, Calibration and Field Test of the Atmospheric Hydrogen Fluoride Recorder, J. Japan Soc. Air Pollution 5 (1), 87 (1970).

5. T. Okita, R. Sugai, and K. Kaneda, Separation and Subsequent Determination of Atmospheric Particulate and Gaseous Fluorides, J. Japan Soc. Air Pollution 5 (1), $88(1970)$.

6. P. Hermann, Measurement of Gaseous Fluoride Compounds in the Outdoor Air and in Industrial Waste Gases, Tech. Ueberwach. (Duesseldorf) 13 (2), 42-45 (1972).

7. Japan Environmental Agency, "Instructions for Air Quality Measurements and Other Environmental Investigations", (1972).

8. N. Gilbert, I. A. Hobbs, and W. D. Sandberg, Absorption of Hydrogen Fluoride in a Limestone-packed Tower, Chem. Eng. Progr. 49, 120-127 (1953).

9. J. S. Lobos, J. P. McGeer, and D. P. Sanderson, Reactivity of Alumina towards Hydrogen Fluoride, American Institute of Mining, Metallurgical, and Petroleum Engineering, New York, N. Y. (1971).

10. J. Jahr, A New Double Filter Method for the Separate Determination of Hydrogen Fluoride and Dust-like Fluorides in the Air, Staub, Reinhaltung Luft 32 (6), 248-252 (1972).

11. J. Biheller and W. Resch, Tests with a Sampling and Measurement Method for Routine Determination of Fluorine in the Lower Atmosphere, Staub, Reinhaltung Luft 31 (1), $9-11$ (1971).

12. J. D. Navratil, "Disposal of Fluorine", Dow Chemical Company, Golden, CO, AEC Contract AT(29-1)-1106 (1968).

13. Y. Naoi, Performance and Problems of Air Filters Impregnated with Alkali, J. Japan Air Cleaning Assoc. $10(6), 53-58(1972)$.

14. T. Okita, Measurement of Hydrogen Fluoride Using Filter Method and Separate Determination of Gaseous and Particulate Fluorides, Environmental Health Report, No. 8, 19-22 (1972).

15. T. Okita, R. Sugai, and K. Kaneda, Collection of a Trace Amount of Hydrogen Fluoride using the Alkaline Filter Method, Koash Eiseiin Kenkyu Hokoku 18 (2), 69 (1969). 
16. C. Huygen, Sampling Hydrogen Fluoride in Air with Impregnated Filter Paper, Ana1. Chim. Acta 29 (5), 448 $(1963)$.

17. G. S. Salyamon, and M. V. Popelkovskaya, Methods for the Determination of Fluoride Ions in Air and Water, Gigiena i Sanit. No. 4, 65-67 (1973).

18. Intersociety Committee, Methods of Air Sampling and Analysis, pp 246-281, American Public Health Assoc., Washington, DC (1972); Am. Ind. Hyg. Assoc. J. 33 (4), $269-278(1972)$.

19. B. S. Marshall and R. Wood, The Determination of Total Fluoride in Air by using a Microdiffusion Technique, Analyst 94 (1119), 493-499 (1969).

20. G. G. Guilbault, Practical Fluorescence, p 245, Marce1 Dekker, Inc., New York, NY (1973).

21. R. J. Thompson, T. B. McMullen, and G. B. Morgan, Fluoride Concentrations in the Ambient Air, J. Air Pollution Control Assoc. 21 (8), 484-487 (1971).

22. M. Buck and H. Stratmann, A Method to Determine Very Small Concentrations of Fluorine Ions in the Atmosphere, Brennstoff-Chem. (Essen) 46 (8), 231-235 (1965).

23. K. Leichnitz, "Drager Detector Tube Handbook".

24. American Public Health Association, American Water Works Assoc., and Water Pollution Control Federation, Standard Methods for the Examination of Water and Wastewater, 13th ed., pp 168-178, American Public Health Assoc., Washington, DC (1971).

25. S. Ito, Methods and Tools for the Measurement of Hydrogen Fluoride and Chlorine Gases, (Fukka suiso gasu, enso gasu no sokuteiho to kiki), PPM (Japan) 3 (11)

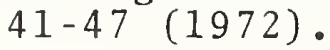

26. J. O. Ivie, D. Thomas, Moyer, and L. F. Zielenski, Automatic Sensing and Recording of Air Pollutants on Citrus Trees, Biomed. Sci. Instruments 1, 45-52 (1964).

27. T. Hagiwara, Measuring Apparatus for Toxic Gases, Fuel and Combustion 38 (12), 1217-1220 (1971).

28. A. van Raay, The Use of Indicator Plants to Estimate Air Pollution by $\mathrm{SO}_{2}$ and $\mathrm{HF}$, Proc. First European Congress Influence Air Pollution Plants Animals, Wageningen, Netherlands (1968). 
29. M. Kusumoto, and T. Toyama, The Micro Analysis of Fluorine by the Linear Wash-out Type Oven and Its Application, Japanese J. Ind. Health 13 (2), 120-127 (1971).

30. F. Feigl, and V. Anger, Spot Tests in Inorganic Ana1ysis, 6th English ed., pp 221-230, Elsevier Publishing Company, New York (1972).

31. J. M. Bewers and F. C. Flack, Determination of Fluorine by Prompt (Gamma)-Radiation from Proton Bombardment, Analyst 94 (1114), 1-14 (1969).

32. S. Ohno, M. Suzuki, M. Kadota, and M. Yatazawa, Determination of Trace Fluorine in Biological Materials by Photonuclear Activation Analysis, Mikrochim. Acta, $\underline{1}$, 61-68 (1973). 
HYDROGEN FLUORIDE IN THE ATMOSPHERE

Tentative Method of the

Physical and Chemical Analysis Branch and Engineering Branch

Analyte: Hydrogen Fluoride

Matrix: Air

Procedure: Ion selective electrode
Method No. P\&CAM

Range: 0.03 to $5000 \mathrm{ppm}$

Precision: Relative standard deviation $\pm 3.4 \%$

Collaboratively Tested: No

Date Issued:

Date Revised:

1. Principle of the Method

1.1 Hydrogen fluoride in air is collected by a sorption tube containing sodium acetate crystals.

1.2 The fluoride, together with the sodium acetate, is dissolved in water.

1.3 The fluoride content in the resultant solution is measured by a fluoride ion selective electrode.

1.4 The amount of fluoride in the sample solution is obtained from a calibration curve established with sodium fluoride standards.

2. Range and Sensitivity

2.1 At an air flow rate of $50 \mathrm{~cm}^{3} / \mathrm{min}$ and a collection time of 4 hours, the upper range of detection is $5000 \mathrm{ppm}$.

2.2 At an air flow rate of $200 \mathrm{~cm}^{3} / \mathrm{min}$ and a collection time of 8 hours, the lower range of detection is $0.03 \mathrm{ppm}$.

2.3 The sensitivity is $2.5 \mu \mathrm{g}$ of fluorine. 
3.1 In the presence of a pH buffer, such as sodium acetate, and a polyvalent anion, such as citrate, there is no interference in the analytical method.

3.2 Elemental fluorine is a positive interferrant, to the extent of its collection efficiency on sodium acetate and hydrolysis to form hydrogen fluoride.

4. Precision and Accuracy

4.1 The relative standard deviation, computed from the results of 20 samples, each with 7 determinations, is $\pm 3.4 \%$ at $3 \mathrm{ppm}$ hydrogen fluoride.

4.2 The accuracy has not been determined. No collaborative tests have been performed on this method. However, the sodium acetate sorption tubes have been shown to be $100 \%$ efficient in collecting hydrogen fluoride, up to a total capacity of $46 \mathrm{mg}$. The accuracy of the analytical method is dependent upon the reliability of the sodium fluoride standards.

5. Advantages and Disadvantages of the Method

5.1 Advantages: This method is highly selective for fluoride ions and very simple in operation. It involves few steps and requires a minimal amount of training. The instrument is readily available commercially and is relatively inexpensive. No special chemical reagents are needed.

5.2 Disadvantages: This method requires a minimum of 20 minutes per run. This includes times for emptying the sorption tube ( 2 minutes), dissolution of the sodium acetate ( 3 minutes), and stabilization of the electrode (15 minutes).

6. Apparatus

6.1 Fluoride ion selective electrode.

6.2 Calomel reference electrode.

$6.3 \mathrm{pH}$ meter with millivolt mode.

6.4 Magnetic stirrer with a variable transformer.

6.5 Analytical balance. 
6.6 Polyethylene beakers, $50 \mathrm{ml}$.

6.7 Plastic coated forceps.

6.8 Straight corrugated forceps.

6.9 Triple beam balance.

6.10 -1iter polyethylene bottles, narrow mouth.

$6.1125-\mathrm{m} 1$ volumetric flasks.

6.12 Wash bottles.

6.13 Stiff wires.

6.14 Sampling apparatus.

6.14.1 Sorption tube for hydrogen fluoride.

6.14.2 Personal sampling pump.

7. Reagents

7.1 Sodium acetate.

7.2 Stock citrate solution: $0.3 \mathrm{~g}$ sodium citrate dissolved in one liter of distilled water.

7.3 Sodium fluoride, dried at $110^{\circ} \mathrm{C}$ for 24 hours and kept in a desiccator.

$7.4 \quad 0.5 \mathrm{~N}$ nitric acid.

8. $\quad$ Procedure

8.1 Collection of samples: hydrogen fluoride in air is collected by the sorption tube with a personal sampling pump. Plastic end caps are placed on the sorption tube after sample is collected.

8.2 Analysis of samples.

8.2.1 The plastic end caps are removed from the sorption tube.

8.2.2 Using a stiff wire, suitably bent, or a pair of straight corrugated forceps, the top wad of cotton in the sorption tube is removed and placed in a polyethylene beaker. 
8.2.3 The top end of the sorption tube is inserted into the neck of a 25-ml volumetric flask, and the sodium acetate crystals are emptied into the flask. The sorption tube may be gently tapped to get as many crystals as possible into the flask.

8.2.4 Using a stiff wire, the bottom wad of cotton is broken loose. The cotton should stay inside the sorption tube.

8.2.5 The inside walls of the sorption tube and the cotton are rinsed with $15-18 \mathrm{ml}$ stock citrate solution. Care must be taken that all the rinse go into the volumetric flask.

8.2.6 The sorption tube is removed from the neck of the volumetric flask.

8.2.7 The cotton in the polyethylene beaker is rinsed with $5 \mathrm{ml}$ stock citrate solution. The rinse is added to the $25-\mathrm{m} 1$ volumetric flask.

8.2.8 The solids in the volumetric flask are dissolved completely.

8.2.9 Stock citrate solution is added to the $25-\mathrm{m} 1$ mark in the volumetric flask, and the solution is mixed thoroughly.

8.2.10 The sample solution is transferred to a 50$\mathrm{m} 1$ polyethylene beaker, and 2 drops of 0.5 $\mathrm{N}$ nitric acid are added.

8.2.11 The fluoride selective electrode and the calomel reference electrode are brought to the sample solution.

8.2.12 The magnetic stirrer is placed in the beaker containing the sample solution, and the variable transformer is turned on to provide gentle stirring of the solution.

8.2.13 At the end of 15 minutes, the $\mathrm{pH}$ meter is set to the millivolt mode and the reading is recorded.

8.2.14 The pH meter is set to "standby" mode. 
8.2.15 The sample solution is removed from the electrodes. The electrodes are rinsed with distilled water thoroughly and then wiped dry with soft tissues. The electrodes are immersed in distilled water when not in use.

9. Calibration and Standards

9.1 Standards

9.1.1 A stock solution is prepared by dissolving $120 \mathrm{~g}$ sodium acetate and $0.3 \mathrm{~g}$ sodium citrate in one liter of distilled water. This stock solution is used for dissolution and dilution of the sodium fluoride standards.

9.1.2 Sodium fluoride, $420 \mathrm{mg}$ weighed to the accuracy of $\pm 0.1 \mathrm{mg}$, is dissolved and diluted to $100.0 \mathrm{ml}$ in a volumetric flask. This makes the $10^{-1} \mathrm{M}$ standard solution.

9.1.3 Sodium fluoride, $420 \mathrm{mg}$ weighed to the accuracy of $\pm 0.1 \mathrm{mg}$, is dissolved and diluted to 1.000 liter in a volumetric flask. This makes the $10^{-2} \mathrm{M}$ standard solution.

$9.1 .410 .0 \mathrm{ml}$ of the $10^{-1} \mathrm{M}$ standard solution is transferred into a volumetric flask and diluted to 1.000 liter. This makes the $10^{-3}$ standard solution.

9.1.5 $10.0 \mathrm{~m} 1$ of the $10^{-2} \mathrm{M}$ standard solution is transferred into a volumetric flask and diluted to 1.000 iiter. This makes the $10^{-4}$ M standard solution.

$9.1 .61 .00 \mathrm{~m} 1$ of the $10^{-2} \mathrm{M}$ standard solution is transferred into a volumetric flask and diluted to 1.000 liter. This makes the $10^{-5}$ M standard solution.

9.1.7 $1.00 \mathrm{ml}$ of the $10^{-3} \mathrm{M}$ standard solution is transferred into a volumetric flask and diluted to 1.000 liter. This makes the $10^{-6}$ M standard solution.

9.2 Calibration Curve

9.2.1 A 25-m1 sample of each of the standard solutions is used to obtain the millivolt reading for the fluoride concentration. 
9.2.2 A plot is made of the millivolt reading versus fluoride concentration. The latter is plotted on logarithmic scale. The plot should give a straight 1 ine down to $10^{5} \mathrm{M}$.

10. Calculations

10.1 The molar concentration of fluoride is read from the calibration curve corresponding to the millivolt reading of the sample solution.

10.2 The amount of fluoride collected in the sorption tube, in mighydrogen fluoride, is calculated as follows:

mg $H F=500 \times$ molar concentration of fluoride.

11. References

11.1 American Public Health Association, American Water Works Association, and Water Pollution Control Federation, "Standard Methods for the Examination of Water and Wastewater", 13th ed., pp 168-178, American Public Health Association, Washington, DC (1971).

11.2 R. A. Durst, "Ion-Selective Electrodes", pp 389394, National Bureau of Standards Special Publication 314, National Bureau of Standards, Washington, DC (1969).

$11.3 \mathrm{~J}$. Wing and J. K. Taylor, "Development of a Solid Sorption Tube for Sampling Hydrogen Fluoride in the Work Atmosphere", National Bureau of Standards Internal Report NBSIR 74-581, National Bureau of Standards, Wașhington, DC (1974). 
MBS. 114A (REV. 7.73)

\begin{tabular}{|c|c|c|c|}
\hline $\begin{array}{l}\text { U.S. DEFT. OF COMM. } \\
\text { EIRLIOGRAPHIC DATA } \\
\text { SHEET }\end{array}$ & $\begin{array}{l}\text { 1. PUBLICATION OR REPORT NO. } \\
\text { NBSIR } 74-581\end{array}$ & $\begin{array}{l}\text { 2. Gov't Accession } \\
\text { No. }\end{array}$ & 3. Recipient's Accession No. \\
\hline \multirow{2}{*}{\multicolumn{3}{|c|}{$\begin{array}{l}\text { 4. TITLE AND SUBCITLE } \\
\text { Development of a Solid Sorption Tube for Sampling } \\
\text { Hydrogen Fluoride in the Work Atmosphere }\end{array}$}} & $\begin{array}{l}\text { 5. Publication Date } \\
\text { October } 1974\end{array}$ \\
\hline & & & 6. Performing Organization Code \\
\hline \multicolumn{3}{|c|}{$\begin{array}{l}\text { 7. AUTHOR(S) } \\
\text { James Wing and John K. Taylor }\end{array}$} & 8. Performing Organ. Report No. \\
\hline \multirow{2}{*}{\multicolumn{3}{|c|}{$\begin{array}{l}\text { 9. PER FORMING ORGANIZATION NAME AND ADDRESS } \\
\text { NATIONAL BUREAU OF STANDARDS } \\
\text { DEPARTMENT OF COMMERCE } \\
\text { WASHINGTON, D.C. } 20234\end{array}$}} & $\begin{array}{l}\text { 10. Project/Task/Work Unit No. } \\
3104458\end{array}$ \\
\hline & & & 11. Contract/Grant No. \\
\hline \multirow{2}{*}{\multicolumn{3}{|c|}{$\begin{array}{l}\text { 12. Sponsoring Organization Name and Complete Address (Street, City, State, } Z I P \text { ) } \\
\text { National Institute for Occupational Safety and Healt } \\
\text { Division of Laboratories and Criteria Development } \\
\text { Cincinnati, Ohio } 45202\end{array}$}} & $\begin{array}{l}\text { 13. Type of Report \& Period } \\
\text { Covered } \\
\text { Final Report } \\
\end{array}$ \\
\hline & & & 14. Sponsoring $\mathrm{Ag}$ \\
\hline
\end{tabular}

15. SUPPLEMENTARY NOTES

16. ABSTRACT (A 200-word or less factual summary of most significant information. If document includes a significant bibliography of literature survey, mention it here.)

The efficiencies of several solid substances in a sorption tube for collecting trace quantities of hydrogen fluoride gas in work atmosphere have been evaluated. Reagent-grade sodium acetate crystals proved to be a very efficient sorbent for hydrogen fluoride. Its solubility in water and $\mathrm{pH}$ buffer properties are highly advantageous for subsequent fluoride determination by the ion selective electrode. Experimental results are presented for collection efficiencies of hydrogen fluoride gas at several concentration levels, flow rates, and collection times, the effects of elevated temperatures and humidity, and also breakthrough, bleed-out, storage and shipment studies. Specifications for construction of the sorption tubes are also given.

17. KEY WORDS (six to twelve entries; alphabetical order; captalize only the first letter of the first key word unless a proper name; separated by semicolons)

Air analysis; air sampling; gas analysis; hydrogen fluoride; industrial hygiene; sodium acetate; sorber; solid; work atmosphere.

18. AVAILABILITY [X Unlimited

For Official Distribution. Do Not Release to NTIS

Order From Sup. of Doc., U.S. Government Printing Office Washington, D.C. 20402, SD Cat. No. C 13

Order From National Technical Information Service (NTIS) Springfield, Virginia 22151

\begin{tabular}{|l|c|}
\hline $\begin{array}{l}\text { 19. SECURITY CLASS } \\
\text { (THIS REPURT) }\end{array}$ & 21. NO. OF PAGES \\
UNCL ASSIFIED & 58 \\
\hline $\begin{array}{l}\text { 20. SECURITY CLASS } \\
\text { (THIS PAGE) } \\
\text { UNCLASSIFIED }\end{array}$ & 22. Price \\
\hline
\end{tabular}





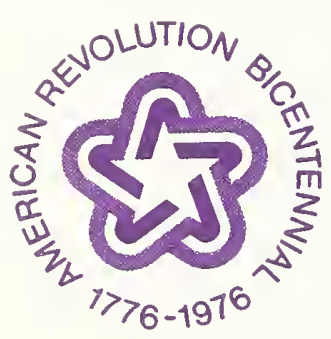

